\title{
Increased Regional Epicardial Fat Volume Associated with Reversible Myocardial Ischemia in Patients with Suspected Coronary Artery Disease
}

\author{
Tuba Khawaja, MD ${ }^{\mathrm{a}}$, Christine Greer, BS ${ }^{\mathrm{a}}$, Samir R. Thadani, MD ${ }^{\mathrm{b}}$, Tomoko S. Kato, MD ${ }^{\mathrm{a}}$, \\ Ketan Bhatia, BS ${ }^{a}$, Daichi Shimbo, MDa ${ }^{a}$ Andrew Konkak, MDa , Sabahat Bokhari, MDa, \\ Andrew J. Einstein, MD, PhDa ${ }^{a}$ and P. Christian Schulze, MD, PhDa \\ a Division of Cardiology, Department of Medicine, New York-Presbyterian Hospital/Columbia \\ University Medical Center, New York, NY \\ b Division of Cardiology, Department of Medicine, Kaiser Permanente South San Francisco \\ Medical Center, South San Francisco, CA
}

\begin{abstract}
Epicardial adipose tissue is a source of pro-inflammatory cytokines and has been linked to the development of coronary artery disease. No study has systematically assessed the relationship between local epicardial fat volume (EFV) and myocardial perfusion defects. We analyzed EFV in patients undergoing SPECT myocardial perfusion imaging combined with computed tomography (CT) for attenuation correction. Low-dose CT without contrast was performed in 396 consecutive patients undergoing SPECT imaging for evaluation of coronary artery disease. Regional thickness, cross-sectional areas, and total EFV were assessed. 295 patients had normal myocardial perfusion scans and 101 had abnormal perfusion scans. Mean EFVs in normal, ischemic, and infarcted hearts were $99.8 \pm 82.3 \mathrm{~cm}^{3}, 156.4 \pm 121.9 \mathrm{~cm}^{3}$, and $96.3 \pm 102.1 \mathrm{~cm}^{3}$, respectively $(P<0.001)$. Reversible perfusion defects were associated with increased local EFV compared to normal perfusion in the distribution of the right $\left(69.2 \pm 51.5 \mathrm{vs} 46.6 \pm 32.0 \mathrm{~cm}^{3} ; P=0.03\right)$ and left anterior descending coronary artery $\left(87.1 \pm 76.4\right.$ vs $\left.46.7 \pm 40.6 \mathrm{~cm}^{3} ; P=0.005\right)$. Our results demonstrate increased regional epicardial fat in patients with active myocardial ischemia compared to patients with myocardial scar or normal perfusion on nuclear perfusion scans. Our results suggest a potential role for cardiac CT to improve risk stratification in patients with suspected coronary artery disease.
\end{abstract}

\section{Keywords}

Epicardial fat; Nuclear perfusion scan; Myocardial ischemia; Cardiac CT; Coronary artery disease

\footnotetext{
Copyright $(2014$ American Society of Nuclear Cardiology

Reprint requests: P. Christian Schulze, MD, PhD, Division of Cardiology, Department of Medicine, New York-Presbyterian Hospital/ Columbia University Medical Center, 622 W168th Street, PH10-203, New York, NY, 10032, USA; pcs2121@ cumc.columbia.edu.

Disclosure

None of the authors has any conflict of interest related to this work.
} 


\section{INTRODUCTION}

Epicardial fat is a layer of adipose tissue adjacent to the myocardium which has long been thought to be biologically inert without specific functions. Several recent reports have linked epicardial adipose tissue to cardiac functional and structural abnormalities including coronary artery disease, atrial fibrillation and heart failure. ${ }^{1-6}$ Epicardial fat has been shown to be a source of inflammatory cytokines such as interleukin (IL)-1 $\beta$, IL-6, monocyte chemotactic protein-1 (MCP-1,) and tumor necrosis factor (TNF)-a. ${ }^{7-11}$ Due to the close anatomic proximity of epicardial fat with coronary arteries, it has been suggested that local inflammation contributes to the buildup of non-calcified plaque within the coronary arteries, resulting in subsequent clinical events. ${ }^{12-14}$

Increased expression of inflammatory mediators has also been demonstrated in coronary arteries associated with critically stenotic and vulnerable plaques. ${ }^{8,15}$ Diffusion of these bioactive molecules into the nearby vascular intima-media layer affects vasomotor function and results in an inflammatory response. ${ }^{2,10}$ Several studies have investigated the relationship between epicardial fat thickness and inflammation using echocardiography, cardiac computed tomography (CT), and conventional angiography. ${ }^{16-18}$ Using cardiac CT, coronary atherosclerosis has been defined primarily as coronary artery calcification or stenosis, while direct functional data of local myocardial perfusion imaging are lacking. ${ }^{19-22}$ A previous study demonstrated that local epicardial fat volume (EFV) in the left atrioventricular groove provides a better assessment of atherogenic risk than total EFV and also showed a relationship between epicardial fat thickness and stenotic coronary artery lesions. ${ }^{22}$ More recently, several studies have demonstrated a relationship between total epicardial and thoracic adipose tissue and myocardial ischemia. ${ }^{12,14}$

Epicardial adipose tissue is highly variable in its distribution along the coronary artery tree and within the atrioventricular grooves. ${ }^{23-25}$ We hypothesized that regional variations of epicardial fat accumulation reflect various degrees of $\mathrm{CAD}$ and link active regional ischemia with abnormalities in local epicardial fat accumulation. We, therefore, analyzed local EFV in a cohort of patients evaluated for CAD with single-photon emission computed tomography (SPECT) myocardial perfusion imaging with non-contrast CT for attenuation correction.

\section{METHODS}

\section{Study Groups}

The cohort consisted of 396 consecutive patients who underwent noninvasive assessment of myocardial perfusion by SPECT in combination with a low radiation dose, non-contrast cardiac CT for attenuation correction. Patients were included consecutively without defined inclusion or exclusion criteria. The indication for the diagnostic procedure was based on the clinical suspicion of significant CAD by the referring physician. Smoking behavior, medical history, and use of cardiovascular medications were assessed by a questionnaire. Height and weight were measured to calculate body mass index. Systolic and diastolic blood pressures were measured, while the patient was in the supine position prior to CT imaging. Subgroup analysis was performed according to nuclear perfusion status and coronary artery calcium 
scores (CCS). The study protocol was approved by the institutional review board of Columbia University.

\section{SPECT Nuclear Perfusion Imaging}

Standardized treadmill exercise testing was performed using a symptom-limited Bruce protocol or pharmacologic testing using adenosine $\left(140 \mu \mathrm{g} \cdot \mathrm{kg}^{-1}\right.$ minute ${ }^{-1}$ infusion rate $)$ for patients unable to exercise. ${ }^{26}$ The occurrence of chest discomfort and ischemic electrocardiographic changes was recorded. At peak exercise, Tc-99m sestamibi was administered intravenously. Stress SPECT imaging was performed 30 minutes to 1 hour later with a high-resolution collimator on a SPECT/CT scanner (Philips Precedence 16P, Philips Medical Systems). CT attenuation was performed using a low-dose CT scan performed on the same scanner as detailed below. All patients also underwent rest imaging with either Tc-99m sestamibi or Tl-201. For each patient, the SPECT images were interpreted by a board-certified nuclear cardiologist blinded to CT EFV analysis findings. Abnormal scans were defined as fixed (scar) or reversible (ischemia) perfusion defects, and partially reversible defects were categorized as myocardial ischemia.

\section{CT Imaging and Analysis of Epicardial Fat Volume and Coronary Artery Calcification}

All CT scans were performed on a single scanner (Philips Precedence 16P, Philips Medical Systems) in spiral mode with pitch of 0.94 , collimation of $16 \times 1.5 \mathrm{~mm}$, tube voltage of 120 $\mathrm{kVp}$, and effective mAs of 25 to 50 , adjusted to patient body habitus (Dose-length product $97 \mathrm{mGy} \cdot \mathrm{cm})$.

Epicardial fat was defined as adipose tissue within the pericardial cavity including pericoronary adipose tissue. EFV was determined by manually tracing areas of tissue between the visceral myocardium and pericardium on consecutive transaxial images and multiplying total area by slice thickness. ${ }^{25}$ Analysis of regionally specific EFV was performed to determine the specific amount of perivascular epicardial fat adjacent to each major coronary artery using the cardiac 17 -segment model ${ }^{27}$ Epicardial fat in or adjacent to the left interventricular groove was identified with the LAD, fat in or adjacent to the left atrioventricular groove with the left circumflex distribution, and fat in or adjacent to the right atrioventricular groove with the right coronary artery distribution. To reduce observer bias, the investigator calculating EFV accumulation was blinded to the results of the nuclear perfusion studies of each patient.

Coronary artery calcium was quantified by semiautomated analysis using the Agatston score (CCS). Total CCS were calculated as the sum of calcified plaque scores of the entire coronary artery tree. Patients were sub-divided into groups based on the CCS defined as $\mathrm{CCS}=0, \mathrm{CCS}=1-99, \mathrm{CCS}=100-399$, and $\mathrm{CCS}>400$.

\section{Statistical Analysis}

Mean value \pm standard deviation are reported for all variables. Normality was evaluated for each variable from normal distribution plots and histograms and by the KolmogorovSmirnov test. Comparisons between two groups for continuous variables were analyzed utilizing Student's $t$ test for variables with normal distribution and the Mann-Whitney $U$ test 
for variables with non-normal distribution. Analysis of variance with Scheffe's F adjustment for multiple comparisons with appropriate post hoc analysis was used to assess differences for more than two group comparisons. Categorical values were compared using chi-square testing. Correlational analysis was performed using Pearson's correlation coefficients. A $P$ value of less than 0.05 was considered significant. Statistical analysis was performed using SPSS (IBM Inc. v18).

\section{RESULTS}

\section{Clinical Characteristics}

A total of 396 patients were consecutively enrolled in this study. Baseline characteristics of all patients are described in Table 1. Analysis for concomitant diseases and medications between the different groups did not reveal major differences except more female subjects, an older age, higher systolic blood pressure and lower left ventricular ejection fraction in the patients with positive perfusion defects compared to patients with normal perfusion imaging. The Framingham Risk Score was $6 \pm 6 \%$ in patients without perfusion defects, $9 \% \pm 7 \%$ in patients with ischemia, and $10 \% \pm 5 \%$ in patients with fixed perfusion defects, respectively $(P=0.007)$.

\section{Image Analysis}

SPECT nuclear perfusion imaging revealed normal myocardial perfusion in 295 patients, reversible myocardial perfusion defects in 66 patients, and fixed myocardial perfusion defects in 35 patients (Table 2). 63 patients showed defects in the LAD territory, 77 in the RCA territory, and 40 in the LCX territory. The CCS were $458 \pm 1118$ in patients without perfusion defects, $357 \pm 776$ in patients with reversible ischemia ( $P=$ NS vs controls) and $516 \pm 1743$ in patients with fixed perfusion effects ( $P=$ NS vs controls and ischemia). Total EFV in patients without perfusion defects was $99.8 \pm 82.3 \mathrm{~cm}^{3}$, which was lower than in those with ischemia $\left(156.4 \pm 121.9 \mathrm{~cm}^{3} ; P=0.001\right.$ vs controls $)$ but similar to those with fixed perfusion defects consistent with infarcted myocardium $\left(96.3 \pm 102.1 \mathrm{~cm}^{3} ; P=\mathrm{NS}\right.$ vs controls) (Table 2). Coronary vessel-specific epicardial fat accumulation subcategorized by perfusion status is described in Figure 1.

Analysis of regionally specific adipose tissue distribution revealed higher EFV surrounding the RCA and LAD in patients with ischemia compared to patients without ischemia and patients with myocardial infarction (Figure 2). Increased regional EFV was limited to the coronary artery supplying that specific ischemic area of myocardium, while the other coronary arteries within the same patient showed normal amounts of epicardial fat. Further, EFV in areas of infarcted myocardium was comparable to non-stenotic coronary arteries of individual patients and also across the study group. Of note, no significant differences were noted in the territory supplied by the LCx (Figure 2). When we tested age, BMI, LDL cholesterol, and EFV as individual factors for their association with myocardial ischemia in a multivariate analysis, we found significant co-regulation between EFV and these established risk factors for the development of coronary artery disease. None of the factors was independently associated with active myocardial ischemia on nuclear perfusion scanning. 
Subgroup analysis of patients based on CCS revealed no significant differences between $\mathrm{CCS}=0$ and CCS $>1$ across all parameters tested except for patients with reduced left ventricular ejection fraction $(\mathrm{LVEF}<55 \%)$ who had higher CCS $(P=0.01)$. All other parameters including age, concomitant diseases, laboratory, and imaging characteristics as well as nuclear stress test findings did not differ significantly between the two groups. In addition, within the ischemia group, EFV was not statistically different between patients with calcium scores of zero and scores greater than zero. No association was found between total or vessel-specific accumulation of epicardial fat and the degree of coronary artery calcification. Finally, no significant correlation was found between age and EFV.

Analysis of patients with and without LV dysfunction revealed that the observed ischemiaassociated increase in EFV was still detectable in patients with reduced LV function. Nevertheless, patients with reduced LV function $(<55 \%)$ had a general decrease in EFV in all groups analyzed compared to normal LV function (Figure 3).

\section{DISCUSSION}

Our current study reveals that patients with myocardial ischemia have increased EFV which is localized adjacent to ischemic myocardium. Further, infarcted myocardial tissue shows levels of EFV comparable to non-ischemic myocardium.

The association between EFV and the severity of coronary artery disease has been described in a number of studies with mixed results. ${ }^{28-32}$ More recent evidence has outlined a possible explanation for these findings by noting a preferential increase in epicardial fat thickness along "vulnerable" non-calcified plaque lesions compared to chronically calcified coronary lesions. ${ }^{28-32}$ Collectively, these observations support the association of increased EFV associated with atherosclerotic coronary artery disease and metabolically active coronary lesions. Alexopoulous et $\mathrm{al}^{28}$ found that epicardial adipose tissue increased in patients with mixed or non-calcified plaques compared to patients with calcified plaques or no plaques which correlates with increased perivascular adipocytokine expression associated with plaque rupture ${ }^{11,33}$ and increased clinical events. ${ }^{12,14}$ These findings suggest that increased EFV might reflect altered metabolic requirements of the myocardium secondary to associated coronary lesions.

In our current study, we measured EFV in patients undergoing SPECT imaging and hypothesized that patients with reversible ischemia would have increased epicardial fat accumulation. We did not exclude patients based on their medical history and included patients with a history of myocardial infarction, cardiomyopathy, and peripheral artery disease. We specifically analyzed regional EFV and tested its association with regional myocardial ischemia and infarction on SPECT nuclear imaging to evaluate the relationship of local EFV and regional myocardial ischemia. Our results demonstrate selective increase of EFV in regions of myocardial ischemia. Our finding suggests that EFV is a novel cardiac imaging factor that is related to other classical risk factors of coronary artery disease. Further, our results reveal a specific role of local epicardial fat adjacent to the ischemic myocardium, while regions of myocardium with normal perfusion or myocardial scarring are characterized by lower EFV. These results are based on the analysis of all three major 
coronary arteries and their corresponding territories. Analysis of the myocardium supplied by the LCx revealed significantly lower epicardial fat and no significant differences in the presence or absence of ischemia most likely associated with specific anatomic determinants of EFV within the distribution of the LCx. This likely reflects that the LCx does not locate within a vertical sulcus but is located in the atrioventricular grove. Further, apical regions of the heart might be more predisposed for accumulation of epicardial fat. This is well in line with our findings of increased EFV in regions of myocardial ischemia that develops distal from an epicardial lesion in the mid-ventricular to apical region of the myocardium within the territory of the ischemic vessel. The CT measurement techniques for epicardial fat are also somehow limited when applied to the horizontal anatomy of the proximal LCx due to slice thickness and motion artifacts.

The finding of increased EFV among patients with myocardial ischemia independent of coronary calcium scores is suggestive of a dynamic inflammatory process likely associated with high risk, non-calcified soft plaques. Recent studies using a variety of techniques have demonstrated the role of cardiac CT in identifying high-risk non-calcified coronary artery lesions. ${ }^{28,29,31,32}$ Visceral adipose tissue correlates with the extent of non-calcified plaque burden and vulnerable plaque characteristics identified by cardiac CT. ${ }^{34}$ It remains conceivable that the increase in epicardial fat observed among patients with ischemia, irrespective of the calcium burden, is reflective of metabolically active, non-calcified plaques.

A limitation of our study is the selection of patients referred for myocardial perfusion scanning for the assessment of coronary artery disease with elevated cardiac risk scores. Our analysis was restricted to epicardial adipose tissue and did not include intrathoracic adipose tissue. We also did not perform contrast $\mathrm{CT}$ for noninvasive angiographic assessment of coronary artery stenosis and coronary plaque composition, and our analysis is based on nonECG-gated CT scans. Further, while our study is limited by the lack of ECG-gating in the CT scans used, literature supports that there is good correlation in quantitative imaging parameters between attenuation correction CT scans and ECG-gated coronary artery calcium scans. ${ }^{35}$ In particular, a recent study from our center has confirmed good agreement in epicardial fat quantification between CAC and attenuation correction CT image acquisition. ${ }^{36}$ Larger study cohorts with a more diverse patient population might be needed to generalize our observations. Our results are mainly based on the positive findings in the distribution of the RCA and LAD and cannot be applied to the LCx. The specific role of preventive medical care and medication cannot be fully assessed in our current analysis. Based on our current study, we cannot fully determine the cause-effect relationship between myocardial ischemia and epicardial fat which might be addressed in further longitudinal follow-up studies.

Future studies should involve determining the association of epicardial fat thickness with non-calcified plaque lesions using contrast cardiac CT and a follow-up analysis of the dynamics of EFV in the regions of myocardial ischemia and infarction over time. Our results may relate to metabolically active epicardial adipose tissue in close proximity to clinically relevant, high-risk stenotic coronary atherosclerotic lesions. One potential future application of our results may be in patients who undergo non-contrast thoracic CT imaging for non- 
cardiac evaluations. In these patients, the detection of significant epicardial fat may suggest an increased risk of significant coronary artery disease with potential ischemia and may warrant further evaluation.

\section{NEW KNOWLEDGE GAINED}

This study shows that patients with myocardial ischemia have increased EFV adjacent to ischemic myocardium, while infarcted myocardium shows EFV comparable to non-ischemic myocardium. Detection of increased epicardial fat depots adjacent to coronary arteries may suggest an increased risk of ischemic coronary artery disease.

\section{Acknowledgement}

This work was supported by Grants from the NHLBI (K23 HL095742, P30 HL101272-01, UL1 RR 024156, HL073029) and the Herbert and Florence Irving Scholar Award to Drs. Schulze and Einstein.

\section{References}

1. Batal O, Schoenhagen P, Shao M, Ayyad AE, Van Wagoner DR, Halliburton SS, et al. Left atrial epicardial adiposity and atrial fibrillation. Circ Arrhythm Electrophysiol. 2010; 3:230-6. [PubMed: 20504944]

2. Doesch C, Haghi D, Fluchter S, Suselbeck T, Schoenberg SO, Michaely H, et al. Epicardial adipose tissue in patients with heart failure. J Cardiovasc Magn Reson. 2010; 12:40. [PubMed: 20624277]

3. Iacobellis G, Corradi D, Sharma AM. Epicardial adipose tissue: Anatomic, biomolecular and clinical relationships with the heart. Nat Clin Pract Cardiovasc Med. 2005; 2:536-43. [PubMed: 16186852]

4. Iacobellis G, Sharma AM. Epicardial adipose tissue as new cardio-metabolic risk marker and potential therapeutic target in the metabolic syndrome. Curr Pharm Des. 2007; 13:2180-4. [PubMed: 17627550]

5. Sacks HS, Fain JN. Human epicardial adipose tissue: A review. Am Heart J. 2007; 153:907-17. [PubMed: 17540190]

6. Vela D, Buja LM, Madjid M, Burke A, Naghavi M, Willerson JT, et al. The role of periadventitial fat in atherosclerosis. Arch Pathol Lab Med. 2007; 131:481-7. [PubMed: 17516753]

7. Baker AR, Harte AL, Howell N, Pritlove DC, Ranasinghe AM, da Silva NF, Youssef EM, et al. Epicardial adipose tissue as a source of nuclear factor-kappa b and c-jun n-terminal kinase mediated inflammation in patients with coronary artery disease. J Clin Endocrinol Metab. 2009; 94:261-7. [PubMed: 18984670]

8. Baker AR, Silva NF, Quinn DW, Harte AL, Pagano D, Bonser RS, et al. Human epicardial adipose tissue expresses a pathogenic profile of adipocytokines in patients with cardiovascular disease. Cardiovasc Diabetol. 2006; 5:1. [PubMed: 16412224]

9. Eiras S, Teijeira-Fernandez E, Shamagian LG, Fernandez AL, Vazquez-Boquete A, GonzalezJuanatey JR. Extension of coronary artery disease is associated with increased il-6 and decreased adiponectin gene expression in epicardial adipose tissue. Cytokine. 2008; 43:174-80. [PubMed: 18562207]

10. Iacobellis G, Barbaro G. The double role of epicardial adipose tissue as pro- and anti-inflammatory organ. Horm Metab Res. 2008; 40:442-5. [PubMed: 18401833]

11. Mazurek T, Zhang L, Zalewski A, Mannion JD, Diehl JT, Arafat H, et al. Human epicardial adipose tissue is a source of inflammatory mediators. Circulation. 2003; 108:2460-6. [PubMed: 14581396]

12. Cheng VY, Dey D, Tamarappoo B, Nakazato R, Gransar H, Miranda-Peats R, et al. Pericardial fat burden on ecg-gated noncontrast ct in asymptomatic patients who subsequently experience adverse cardiovascular events. JACC Cardiovasc Imaging. 2010; 3:352-60. [PubMed: 20394896] 
13. Mahabadi AA, Reinsch N, Lehmann N, Altenbernd J, Kalsch H, Seibel RM, et al. Association of pericoronary fat volume with atherosclerotic plaque burden in the underlying coronary artery: A segment analysis. Atherosclerosis. 2010; 211:195-9. [PubMed: 20223460]

14. Tamarappoo B, Dey D, Shmilovich H, Nakazato R, Gransar H, Cheng VY, et al. Increased pericardial fat volume measured from noncontrast ct predicts myocardial ischemia by spect. JACC Cardiovasc Imaging. 2010; 3:1104-12. [PubMed: 21070997]

15. Chaowalit N, Somers VK, Pellikka PA, Rihal CS, Lopez-Jimenez F. Subepicardial adipose tissue and the presence and severity of coronary artery disease. Atherosclerosis. 2006; 186:354-9. [PubMed: 16183065]

16. Ahn SG, Lim HS, Joe DY, Kang SJ, Choi BJ, Choi SY, et al. Relationship of epicardial adipose tissue by echocardiography to coronary artery disease. Heart (British Cardiac Society). 2008; 94:e7. [PubMed: 17923467]

17. Eroglu S, Sade LE, Yildirir A, Bal U, Ozbicer S, Ozgul AS, et al. Epicardial adipose tissue thickness by echocardiography is a marker for the presence and severity of coronary artery disease. NMCD. 2009; 19:211-7. [PubMed: 18718744]

18. Gorter PM, de Vos AM, van der Graaf Y, Stella PR, Doevendans PA, Meijs MF, et al. Relation of epicardial and pericoronary fat to coronary atherosclerosis and coronary artery calcium in patients undergoing coronary angiography. Am J Cardiol. 2008; 102:380-5. [PubMed: 18678291]

19. de Vos AM, Prokop M, Roos CJ, Meijs MF, van der Schouw YT, Rutten A, et al. Peri-coronary epicardial adipose tissue is related to cardiovascular risk factors and coronary artery calcification in post-menopausal women. Eur Heart J. 2008; 29:777-83. [PubMed: 18156138]

20. Greif M, Becker A, von Ziegler F, Lebherz C, Lehrke M, Broedl UC, et al. Pericardial adipose tissue determined by dual source ct is a risk factor for coronary atherosclerosis. Arterioscler Thromb Vasc Biol. 2009; 29:781-6. [PubMed: 19229071]

21. Rosito GA, Massaro JM, Hoffmann U, Ruberg FL, Mahabadi AA, Vasan RS, et al. Pericardial fat, visceral abdominal fat, cardiovascular disease risk factors, and vascular calcification in a community-based sample: The framingham heart study. Circulation. 2008; 117:605-13. [PubMed: 18212276]

22. Wang TD, Lee WJ, Shih FY, Huang CH, Chen WJ, Lee YT, et al. Association of epicardial adipose tissue with coronary atherosclerosis is region-specific and independent of conventional risk factors and intra-abdominal adiposity. Atherosclerosis. 2010; 213:279-87. [PubMed: 20801451]

23. Abbara S, Desai JC, Cury RC, Butler J, Nieman K, Reddy V. Mapping epicardial fat with multidetector computed tomography to facilitate percutaneous transepicardial arrhythmia ablation. Eur J Radiol. 2006; 57:417-22. [PubMed: 16434161]

24. Gorter PM, van Lindert AS, de Vos AM, Meijs MF, van der Graaf Y, Doevendans PA, et al. Quantification of epicardial and peri-coronary fat using cardiac computed tomography; reproducibility and relation with obesity and metabolic syndrome in patients suspected of coronary artery disease. Atherosclerosis. 2008; 197:896-903. [PubMed: 17884060]

25. Nichols JH, Samy B, Nasir K, Fox CS, Schulze PC, Bamberg F, et al. Volumetric measurement of pericardial adipose tissue from contrast-enhanced coronary computed tomography angiography:A reproducibility study. J Cardiovasc Comput Tomogr. 2008; 2:288-95. [PubMed: 19083964]

26. Gibbons RJ, Balady GJ, Bricker JT, Chaitman BR, Fletcher GF, Froelicher VF, et al. Acc/aha 2002 guideline update for exercise testing: Summary article: A report of the american college of cardiology/american heart association task force on practice guidelines (committee to update the 1997 exercise testing guide-lines). Circulation. 2002; 106:1883-92. [PubMed: 12356646]

27. Hendel RC, Budoff MJ, Cardella JF, Chambers CE, Dent JM, Fitzgerald DM, et al. Acc/aha/acr/ase/asnc/hrs/nasci/rsna/saip/scai/ scct/scmr/sir 2008 key data elements and definitions for cardiac imaging a report of the american college of cardiology/american heart association task force on clinical data standards (writing committee to develop clinical data standards for cardiac imaging). J Am Coll Cardiol. 2009; 53:91-124. [PubMed: 19118731]

28. Alexopoulos N, McLean DS, Janik M, Arepalli CD, Stillman AE, Raggi P. Epicardial adipose tissue and coronary artery plaque characteristics. Atherosclerosis. 2010; 210:150-4. [PubMed: 20031133] 
29. Foster G, Shah H, Sarraf G, Ahmadi N, Budoff M. Detection of noncalcified and mixed plaque by multirow detector computed tomography. Expert Rev Cardiovasc Ther. 2009; 7:57-64. [PubMed: 19105767]

30. Janik M, Hartlage G, Alexopoulos N, Mirzoyev Z, McLean DS, Arepalli CD, et al. Epicardial adipose tissue volume and coronary artery calcium to predict myocardial ischemia on positron emission tomography-computed tomography studies. J Nucl Cardiol. 2010; 17:841-7. [PubMed: 20440592]

31. Kitagawa T, Yamamoto H, Horiguchi J, Ohhashi N, Tadehara F, Shokawa T, et al. Characterization of noncalcified coronary plaques and identification of culprit lesions in patients with acute coronary syndrome by 64-slice computed tomography. JACC Cardiovasc Imaging. 2009; 2:153-60. [PubMed: 19356549]

32. Pundziute G, Schuijf JD, Jukema JW, Decramer I, Sarno G, Vanhoenacker PK, et al. Head-to-head comparison of coronary plaque evaluation between multislice computed tomography and intravascular ultrasound radiofrequency data analysis. JACC Cardiovasc Interv. 2008; 1:176-82. [PubMed: 19463297]

33. Laine P, Kaartinen M, Penttila A, Panula P, Paavonen T, Kovanen PT. Association between myocardial infarction and the mast cells in the adventitia of the infarct-related coronary artery. Circulation. 1999; 99:361-9. [PubMed: 9918522]

34. Ohashi N, Yamamoto H, Horiguchi J, Kitagawa T, Kunita E, Utsunomiya H, et al. Association between visceral adipose tissue area and coronary plaque morphology assessed by CT angiography. JACC Cardiovasc Imaging. 2010; 3:908-17. [PubMed: 20846624]

35. Einstein AJ, Johnson LL, Bokhari S, Son J, Thompson RC, Bateman TM, et al. Agreement of visual estimation of coronary artery calcium from low-dose CT attenuation correction scans in hybrid PET/CT and SPECT/CT with standard agatston score. J Am Coll Cardiol. 2010; 56:191421. [PubMed: 21109114]

36. Dharawat A, Kontak A, Kinkhabwala M, Dey D, Jin Z, Bokhari J, et al. Epicardial fat volume: A comparison between coronary artery calcium and attenuation correction image acquisition (abstract \#222-04). J Nucl Cardiol. 2013; 20:672-3. 


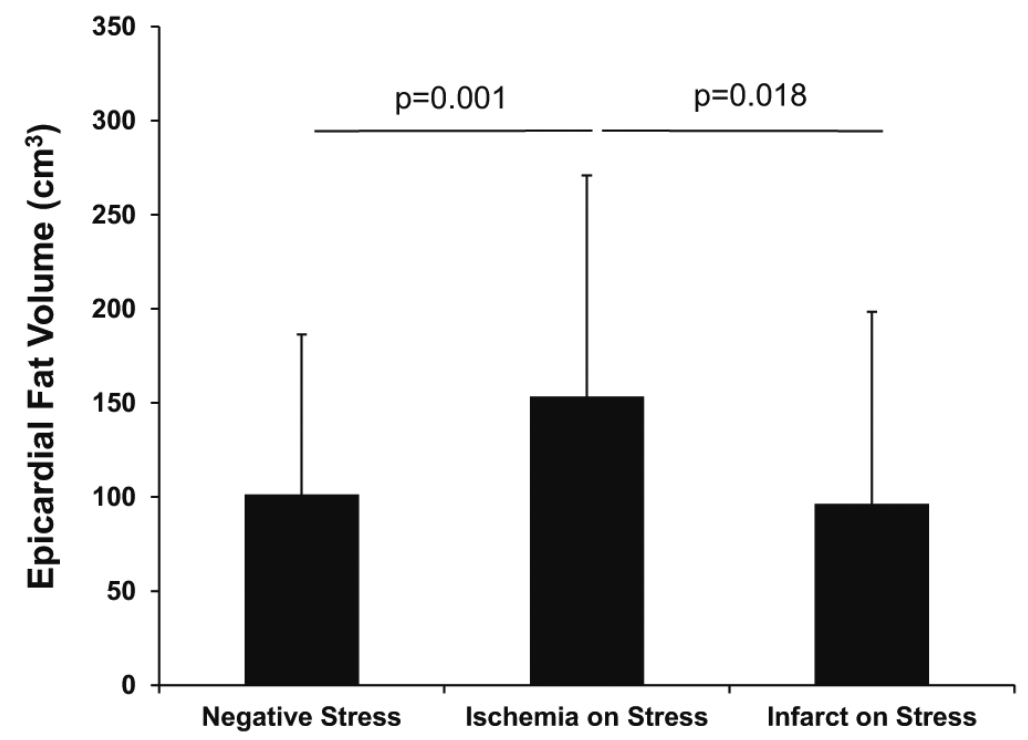

Figure 1.

EFV and SPECT myocardial perfusion imaging. Patients with evidence of ischemia on SPECT myocardial perfusion imaging showed a significant increase in EFV compared to patients with normal nuclear perfusion imaging and patients with non-reversible perfusion defects suggestive of previous myocardial infarction. 


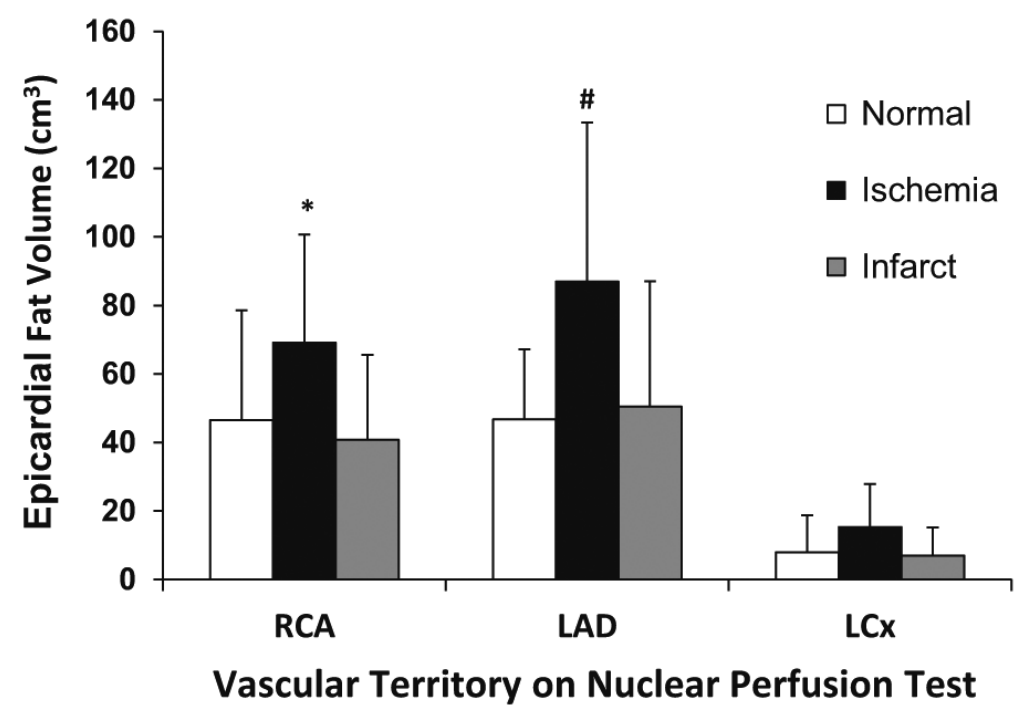

Figure 2.

Regional EFV subcategorized according to myocardial perfusion status. Myocardial ischemia is associated with significantly elevated EFV in the distribution of the right coronary artery (RCA) and left anterior descending coronary artery (LAD). No significant differences between normal perfusion imaging and ischemia are detectable in the region of the left circumflex artery (LCx). EFV in the territory of the LCx is considerably smaller compared to RCA and LAD territories in the presence of both normal and stenotic coronary arteries $\left({ }^{*} P<0.05\right.$ vs normal $\mathrm{RCA} ;{ }^{*} P<0.01$ vs normal LAD; ${ }^{\dagger} P<0.05$ vs LAD and RCA. 
LV Function normal (EF $>55 \%)$

LV Dysfunction (EF<55\%)

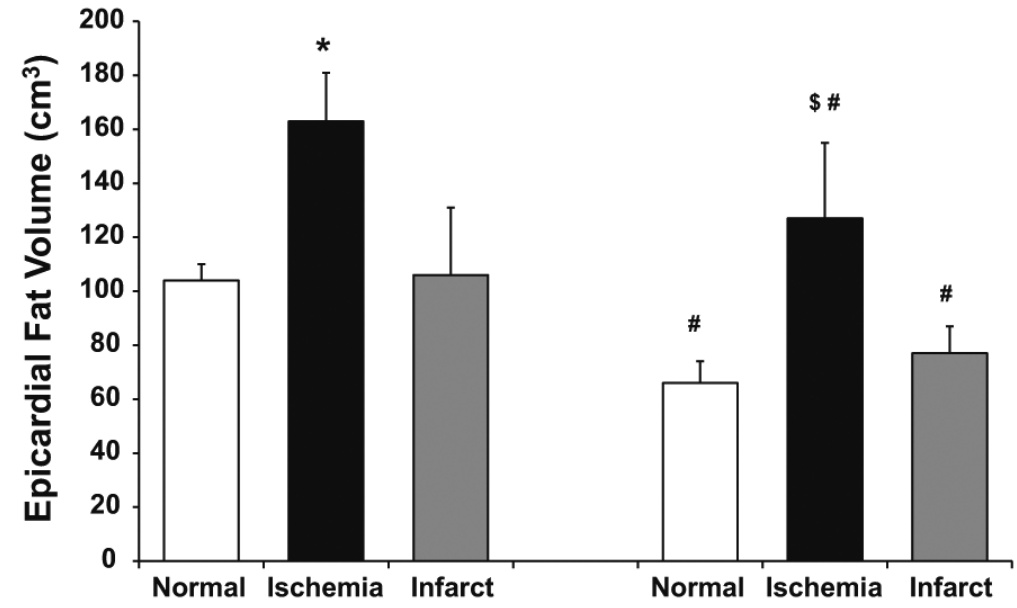

Figure 3.

EFV in patients with normal and decreased LV function subcategorized according to myocardial perfusion status. LV dysfunction is associated with a uniform decrease in EPV but preserved ischemia-associated increase compared to both patients with normal perfusion imaging and patients with evidence of myocardial scarring $\left({ }^{*} P<0.01\right.$ vs normal; ${ }^{\#} P<0.01$ vs normal perfusion but reduced LV function; ${ }^{\$} P<0.05$ vs the corresponding group with normal LV function). 
Table 1

Baseline characteristics

\begin{tabular}{|c|c|c|c|c|c|c|c|}
\hline & \multirow[b]{2}{*}{$\begin{array}{c}\text { Normal cardiac } \\
\text { perfusion }(\mathbf{N}=\mathbf{2 9 5})\end{array}$} & \multicolumn{6}{|c|}{ Abnormal cardiac perfusion on nuclear perfusion imaging } \\
\hline & & $\begin{array}{l}\text { All defects } \\
(\mathrm{N}=101)\end{array}$ & $\begin{array}{l}\text { Vs normal } \\
p \text { value }\end{array}$ & $\begin{array}{c}\text { Ischemia } \\
(\mathbf{N}=66)\end{array}$ & $\begin{array}{l}\text { Vs normal } \\
p \text { value }\end{array}$ & $\begin{array}{l}\text { Infarction } \\
(\mathbf{N}=\mathbf{3 5})\end{array}$ & $\begin{array}{l}\text { Vs normal } \\
p \text { value }\end{array}$ \\
\hline \multicolumn{8}{|l|}{ Demographics } \\
\hline Age (years) & $54.2 \pm 10.6$ & $58.7 \pm 10.7$ & $<0.001$ & $59.3 \pm 9.8$ & 0.008 & $57.2 \pm 12.1$ & $<0.001$ \\
\hline $\begin{array}{l}\text { Body mass index } \\
\left(\mathrm{kg} \cdot \mathrm{m}^{-2}\right)\end{array}$ & $29.3 \pm 6.1$ & $30.2 \pm 7.1$ & 0.78 & $30.9 \pm 7.4$ & 0.69 & $28.6 \pm 5.9$ & 0.76 \\
\hline Female & $165(56 \%)$ & $49(49 \%)$ & 0.038 & $30(48 \%)$ & 0.22 & $19(54 \%)$ & 0.31 \\
\hline $\begin{array}{l}\text { Systolic blood } \\
\text { pressure }(\mathrm{mmHg})\end{array}$ & $132 \pm 17$ & $139 \pm 20$ & 0.008 & $140 \pm 18$ & 0.035 & $138 \pm 17$ & 0.029 \\
\hline $\begin{array}{l}\text { Diastolic blood } \\
\text { pressure (mmHg) }\end{array}$ & $77 \pm 12$ & $78 \pm 13$ & 0.71 & $77 \pm 15$ & 0.66 & $78 \pm 12$ & 0.23 \\
\hline $\begin{array}{l}\text { Left ventricular } \\
\text { ejection fraction }(\%)\end{array}$ & $61 \pm 10$ & $57 \pm 13$ & $<0.001$ & $58 \pm 12$ & 0.07 & $54 \pm 16$ & 0.001 \\
\hline Hypertension & $223(66 \%)$ & $47(82 \%)$ & 0.06 & $33(83 \%)$ & 0.75 & $14(82 \%)$ & 0.29 \\
\hline Diabetes mellitus & $80(24 \%)$ & $21(37 \%)$ & 0.07 & $11(28 \%)$ & 0.19 & $10(59 \%)$ & 0.005 \\
\hline Hyperlipidemia & $119(35 \%)$ & $24(42 \%)$ & 0.07 & $16(40 \%)$ & 0.79 & $8(47 \%)$ & 0.14 \\
\hline Smoking history & $59(18 \%)$ & $11(19 \%)$ & 0.87 & $8(20 \%)$ & 0.78 & $3(18 \%)$ & 0.91 \\
\hline $\begin{array}{l}\text { Framingham Risk } \\
\text { Score }(\%)\end{array}$ & $6 \pm 6$ & $10 \pm 7$ & 0.007 & $9 \pm 7$ & 0.11 & $10 \pm 5$ & 0.14 \\
\hline Aspirin & $73(22 \%)$ & $14(25 \%)$ & 0.16 & $12(30 \%)$ & 0.17 & $2(12 \%)$ & 0.49 \\
\hline Statins & $74(22 \%)$ & $14(25 \%)$ & 0.5 & $10(25 \%)$ & 0.73 & $4(24 \%)$ & 0.41 \\
\hline Insulin & $22(7 \%)$ & $3(5 \%)$ & 0.72 & $3(8 \%)$ & 0.82 & $0(0 \%)$ & 0.32 \\
\hline $\begin{array}{l}\text { Oral antidiabetic } \\
\text { agents }\end{array}$ & $18(5 \%)$ & $3(5 \%)$ & 0.94 & $3(8 \%)$ & 0.5 & $0(0 \%)$ & 0.37 \\
\hline Diuretics & $49(15 \%)$ & $11(19 \%)$ & 0.32 & $8(20 \%)$ & 0.22 & $3(18 \%)$ & 0.46 \\
\hline ACE inhibitors & $33(10 \%)$ & $8(14 \%)$ & 0.24 & $7(18 \%)$ & 0.12 & $1(6 \%)$ & 0.76 \\
\hline$\beta$-blockers & $58(17 \%)$ & $11(19 \%)$ & 0.54 & $8(20 \%)$ & 0.66 & $3(18 \%)$ & 0.6 \\
\hline $\begin{array}{l}\text { Calcium channel } \\
\text { blockers }\end{array}$ & $43(13 \%)$ & $9(16 \%)$ & 0.39 & $7(18 \%)$ & 0.38 & $2(12 \%)$ & 0.81 \\
\hline \multicolumn{8}{|l|}{ Laboratory characteristics } \\
\hline $\begin{array}{l}\text { Creatinine } \\
\quad\left(\mathrm{mmol} \cdot \mathrm{dL}^{-1}\right)\end{array}$ & $1.65 \pm 1.95$ & $1.6 \pm 1.74$ & 0.15 & $1.7 \pm 1.9$ & 0.06 & $1.4 \pm 1.5$ & 0.007 \\
\hline $\begin{array}{l}\text { Blood urea nitrogen } \\
\left(\mathrm{mg} \cdot \mathrm{dL}^{-1}\right)\end{array}$ & $21.0 \pm 15.1$ & $24.3 \pm 14.8$ & 0.17 & $22 \pm 14$ & 0.16 & $23 \pm 17$ & 0.79 \\
\hline $\begin{array}{l}\text { Total cholesterol } \\
\left(\mathrm{mg} \cdot \mathrm{dL}^{-1}\right)\end{array}$ & $183 \pm 50$ & $171 \pm 46$ & 0.1 & $173 \pm 47$ & 0.19 & $181 \pm 56$ & 0.27 \\
\hline $\begin{array}{l}\text { High density } \\
\text { lipoprotein } \\
\left(\mathrm{mg} \cdot \mathrm{dL}^{-1}\right)\end{array}$ & $46 \pm 17$ & $45 \pm 12$ & 0.59 & $48 \pm 12$ & 0.63 & $45 \pm 12$ & 0.76 \\
\hline $\begin{array}{r}\text { Low density } \\
\text { lipoprotein } \\
\left(\mathrm{mg} \cdot \mathrm{dL}^{-1}\right)\end{array}$ & $112 \pm 44$ & $95 \pm 34$ & 0.068 & $97 \pm 32$ & 0.002 & $116 \pm 39$ & 0.17 \\
\hline $\begin{array}{l}\text { Triglycerides } \\
\left(\mathrm{mg} \cdot \mathrm{dL}^{-1}\right)\end{array}$ & $142 \pm 86$ & $130 \pm 114$ & 0.74 & $141 \pm 126$ & 0.41 & $112 \pm 47$ & 0.046 \\
\hline
\end{tabular}




\begin{tabular}{|c|c|c|c|c|c|c|c|}
\hline & \multirow[b]{2}{*}{$\begin{array}{c}\text { Normal cardiac } \\
\text { perfusion }(N=295)\end{array}$} & \multicolumn{6}{|c|}{ Abnormal cardiac perfusion on nuclear perfusion imaging } \\
\hline & & $\begin{array}{l}\text { All defects } \\
(N=101)\end{array}$ & $\begin{array}{l}\text { Vs normal } \\
p \text { value }\end{array}$ & $\begin{array}{c}\text { Ischemia } \\
(\mathbf{N}=\mathbf{6 6})\end{array}$ & $\begin{array}{l}\text { Vs normal } \\
p \text { value }\end{array}$ & $\begin{array}{l}\text { Infarction } \\
(\mathbf{N}=\mathbf{3 5})\end{array}$ & $\begin{array}{l}\text { Vs normal } \\
p \text { value }\end{array}$ \\
\hline $\begin{array}{l}\text { Alanine } \\
\text { aminotransferase } \\
\left(\mathrm{U} \cdot \mathrm{L}^{-1}\right)\end{array}$ & $22 \pm 17$ & $23 \pm 23$ & 0.52 & $22 \pm 28$ & 0.8 & $24 \pm 30$ & 0.44 \\
\hline $\begin{array}{l}\text { Aspartate } \\
\text { aminotransferase } \\
\left(\mathrm{U} \cdot \mathrm{L}^{-1}\right)\end{array}$ & $25 \pm 17$ & $25 \pm 23$ & 0.54 & $23 \pm 16$ & 0.56 & $29 \pm 40$ & 0.26 \\
\hline $\begin{array}{l}\text { Total bilirubin } \\
\left(\mathrm{mg} \cdot \mathrm{dL}^{-1}\right)\end{array}$ & $1.3 \pm 8$ & $0.7 \pm 0.9$ & 0.036 & $0.6 \pm 0.3$ & 0.026 & $0.9 \pm 1.4$ & 0.13 \\
\hline Albumin $\left(g \cdot d L^{-1}\right)$ & $4.1 \pm 0.5$ & $4.1 \pm 0.5$ & 0.29 & $4.1 \pm 0.5$ & 0.69 & $4.0 \pm 0.5$ & 0.55 \\
\hline $\begin{array}{l}\text { Fasting glucose } \\
\left(\mathrm{mg} \cdot \mathrm{dL}^{-1}\right)\end{array}$ & $115 \pm 53$ & $111 \pm 48$ & 0.49 & $111 \pm 46$ & 0.76 & $118 \pm 73$ & 0.21 \\
\hline
\end{tabular}




\section{Table 2}

Imaging characteristics

\begin{tabular}{lccccccc}
\hline & $\begin{array}{c}\text { Normal cardiac } \\
\text { perfusion } \\
(\mathbf{N}=\mathbf{2 9 5})\end{array}$ & $\begin{array}{c}\text { All defects } \\
(\mathbf{N}=\mathbf{1 0 1})\end{array}$ & $\begin{array}{c}\text { vs normal } \\
\boldsymbol{p} \text { value }\end{array}$ & $\begin{array}{c}\text { Ischemia } \\
(\mathbf{N}=\mathbf{6 6})\end{array}$ & $\begin{array}{c}\text { vs normal } \\
\boldsymbol{p} \text { value }\end{array}$ & $\begin{array}{c}\text { Infarction } \\
(\mathbf{N}=\mathbf{3 5})\end{array}$ & $\begin{array}{c}\text { vs normal } \\
\boldsymbol{p} \text { value }\end{array}$ \\
\hline EFV $\left(\mathrm{cm}^{3}\right)$ & & & & & & & \\
$\quad$ Total EFV $\left(\mathrm{cm}^{3}\right)$ & $99.8 \pm 82.3$ & $135.5 \pm 118.4$ & 0.002 & $156.4 \pm 121.9$ & $<0.0001$ & $96.3 \pm 102.1$ & 0.99 \\
$\quad$ Left anterior descending & $45.1 \pm 31.9$ & $66.9 \pm 70.8$ & 0.04 & $76.0 \pm 73.2$ & 0.005 & $45.3 \pm 61.7$ & 0.95 \\
Left circumflex & $8.1 \pm 10.7$ & $13.1 \pm 12.5$ & 0.23 & $15.1 \pm 12.2$ & 0.37 & $6.8 \pm 8.2$ & 0.82 \\
Right & $48.3 \pm 31.9$ & $53.7 \pm 42.7$ & 0.46 & $57.4 \pm 47.1$ & 0.03 & $44.9 \pm 29.0$ & 0.98 \\
Coronary artery calcium score & & & & & & & \\
$\quad$ Total calcium score & $458 \pm 1118$ & $731 \pm 1522$ & 0.17 & $357 \pm 776$ & 0.19 & $516 \pm 1743$ & 0.1 \\
Left main & $51 \pm 101$ & $115 \pm 159$ & 0.043 & $109 \pm 135$ & 0.19 & $126 \pm 203$ & 0.42 \\
Left anterior descending & $246 \pm 488$ & $371 \pm 663$ & 0.17 & $337 \pm 442$ & 0.16 & $422 \pm 914$ & 0.19 \\
Left circumflex & $205 \pm 762$ & $249 \pm 456$ & 0.75 & $228 \pm 409$ & 0.72 & $292 \pm 558$ & 0.27 \\
Right & $194 \pm 446$ & $274 \pm 713$ & 0.48 & $198 \pm 322$ & 0.79 & $493 \pm 1328$ & 0.81 \\
\hline
\end{tabular}

